\title{
Biogeographical aspects of the occurrence of Nyssomyia neivai and Nyssomyia intermedia (Diptera: Psychodidae) in a sympatric area of the Brazilian savannah
}

\author{
Lara Saraiva/ ${ }^{+}$, Gustavo Mayr de Lima Carvalho, Cristiani de Castilho Sanguinette, \\ Deborah Aparecida Alves de Carvalho, José Dilermando Andrade Filho
}

Grupo de Estudos em Leishmanioses, Centro de Pesquisas René Rachou-Fioruz, Belo Horizonte, MG, Brasil

Nyssomyia intermedia and Nyssomyia neivai constitute a species complex associated with Leishmania transmission. The aim of this study was to analyse the ecological profiles of the Ny. intermedia and $\mathrm{Ny}$. neivai populations in a sympatric area in the Brazilian savannah along the banks of the Velhas River. Captures were performed from July 2003-June 2005 in two distinct environments: a gallery forest with various degrees of anthropogenic modification and animal shelters. A total of 20,508 $\mathrm{Ny}$. neivai (86\%) and $\mathrm{Ny}$. intermedia (14\%) sandflies were collected. The difference between the proportions of the sandflies that were collected ( $\mathrm{Ny}$. neivai/Ny. intermedia) per bank was significant. The right bank presented a greater number of sandflies (65\%) and more preserved vegetation. The abundance of $\mathrm{Ny}$. neivai was higher than that of $\mathrm{Ny}$. intermedia on both banks. The results demonstrate that anthropic activities can affect the sandfly populations in this area, thereby leading to a reduction in species abundance. Nevertheless, the environments with higher levels of antropogenic modification displayed sandfly population numbers that favour the Leishmania transmission cycle.

Key words: Nyssomyia intermedia - Nyssomyia neivai - Brazilizian savannah - Velhas River

Brazil has a diversified and widely distributed sandfly fauna and leishmaniasis represents a significant public health problem (MS 2006). According to Andrade Filho et al. (2001), the adaptability of sandflies to the human environment may lead to an increase in the number of leishmaniasis cases due to devastation of natural areas and the consequent destruction of the wild habitat of sandflies.

Savannah vegetation, known as Cerrado in Brazil, occupies an area of over two million $\mathrm{km}^{2}$, thereby representing $22 \%$ of the national territory. The Cerrado biome is rich in both species biodiversity and abundance and represents a top priority in terms of conservation. Despite the ecological significance of this biome, it has been understudied, especially with respect to its insect fauna (Myers et al. 2000, WWF 2011).

Deforestation may be observed in the Brazilian Cerrado as in other biomes. Studies suggest that approximately $20 \%$ of the Cerrado vegetation remains relatively pristine (WWF 2011). Deforestation also affects the gallery forests on Cerrado riverbanks due to the establishment of ranches and farms.

Nyssomyia intermedia and Nyssomyia neivai constitute a species complex associated with Leishmania transmission (Andrade Filho et al. 2003). One of these two species has always predominated in all of the municipalities of the state of Minas Gerais (MG), where they occur in sympatry (Andrade Filho et al. 2007). These species

Financial support: CPqRR/FIOCRUZ, CNPq, FAPEMIG

+ Corresponding author: lara@cpqrr.fiocruz.br

Received 12 February 2012

Accepted 29 June 2012 are found along rivers, which may act as geographical barriers to their dispersion (Andrade Filho et al. 2007).

Collections performed on the left bank of the Velhas River demonstrated the predominant occurrence of $N y$. intermedia over $N y$. neivai and other species in the municipality of Lassance in 1997 (unpublished data). In contrast, $N y$. neivai predominated in captures performed on the left bank of the river in 2002 in a village in the municipality of Corinto, which is approximately $8 \mathrm{~km}$ from Lassance (unpublished data). Ny. neivai and $N y$. intermedia were recorded in sympatry in the municipalities of Pirapora and Arinos, which are located approximately $75 \mathrm{~km}$ and $360 \mathrm{~km}$ north of Lassance, respectively (Andrade Filho et al. 2007).

Research involving the sandfly fauna in various localities in the Cerrado biome, including Lassance and Corinto, is scarce. Knowledge of seasonal and other behavioural aspects of the sandfly species that occur in this region is of great importance for the entomology and biodiversity of the Cerrado biome. These data may provide information regarding the Leishmania vector species necessary for the control of cutaneous and visceral forms of leishmaniasis.

Twenty-four cases of American tegumentary leishmaniasis (ATL) were recorded in Lassance and 37 in Corinto in both urban and rural areas between 19861999. In the latter municipality during the same period, one autochthonous case of visceral leishmaniasis (VL) was also reported (Department of Health of the State of Minas Gerais). Between 2001-2011, seven cases of ATL were recorded in Lassance and five were observed in Corinto, though there were no reported cases of VL.

The aim of this study was to analyse the ecological profiles of the Ny. intermedia and Ny. neivai populations in Lassance and Corinto. 


\section{MATERIALS AND METHODS}

Study area - The municipalities of Lassance (17 $\left.7^{\circ} 53^{\prime} 12^{\prime \prime} \mathrm{S} 44^{\circ} 34^{\prime} 39^{\prime \prime} \mathrm{W}\right)$ and Corinto (18 $22^{\prime} 51^{\prime \prime} \mathrm{S}$ $44^{\circ} 27^{\prime} 23^{\prime \prime} \mathrm{W}$ ) are located in the region of the upper and middle reaches of the São Francisco River, MG, on the banks of the Velhas River. Lassance covers an area of $3.214 \mathrm{~km}^{2}$, which includes 6,554 inhabitants, whereas Corinto covers an area of $2.541 \mathrm{~km}^{2}$ and has 24,678 inhabitants. The main economic activities of the region are agriculture, cattle breeding and fishing. The mean annual temperature is approximately $23^{\circ} \mathrm{C}$ (Fig. 1).

Collections - Captures were performed over two 12month periods, the first of which extended from July 2003-June 2004, while the second was from August 2004-July 2005. Due to operational problems, the study site locations and the sampling methodology varied between the two periods.

First period - Samplings were performed monthly over two consecutive nights using 16 Falcão light traps (Falcão 1981) installed in two environments: the gallery forest and animal shelters. The traps operated from 06:00 p.m.-06:00 a.m. The total sampling time per trap was $288 \mathrm{~h}$ and 4.608 total hours of sampling were conducted. The traps were hung at a radius of $15 \mathrm{~m}$ from each other at each collection site. Collections were performed on both banks of the Velhas River in both muncipalities. Eight light traps were used in each area, with four being placed on each bank of the river.

Muncipality of Corinto - The sampled sites were situated in a fishing village and on farms approximatly $8 \mathrm{~km}$ from Lassance. Four traps were hung in the gallery forest on each bank \{collection sites A [17 ${ }^{\circ} 58.141^{\prime}$ 'S $44^{\circ} 32.392^{\prime} \mathrm{W}, 494 \mathrm{~m}$ above sea level (a.s.l.)] and B (17 $58.115^{\circ} \mathrm{S} 44^{\circ} 32.581^{\prime} \mathrm{W}, 503 \mathrm{~m}$ a.s.l.) (Supplementary data) $\}$. The average width of the river was $198 \mathrm{~m}$.

Muncipality of Lassance - The sampled sites were located on fishermens' small holdings situated in the rural area approximately $3 \mathrm{~km}$ from Lassance. On the left bank, one trap was installed in a hen house, one in a cattle shelter and two were hung in the gallery forest [collection site C (17 $54.859^{\prime} \mathrm{S} 44^{\circ} 34.410^{\prime} \mathrm{W}, 505 \mathrm{~m}$ a.s.l.) (Supplementary data)]. On the right bank, one trap was hung in a hen house, one in a goat shelter and two were hung in the gallery forest [collection site D (17 $54.739^{\prime} \mathrm{S}$ $44^{\circ} 34.460^{\prime} \mathrm{W}, 509 \mathrm{~m}$ a.s.l.) (Table I)]. The average width of the river was $149 \mathrm{~m}$.

Second period - Twelve Falcão light traps were hung each month over two consecutive nights (from August 2004-June 2005) in two types of environments: the gallery forest and animal shelters. The traps were exposed from 06:00 p.m.-06:00 a.m. The total sampling time per trap was $288 \mathrm{~h}$ and a total of $1.728 \mathrm{~h}$ of sampling were conducted. The traps were hung in a radius of $15 \mathrm{~m}$ at all collection points.

Collections were performed exclusively in Lassance in two distinct areas with three traps on each bank of the river. One of the collection areas was the same as in the first period (sites C and D) (Supplementary data).
The other collection sites [collection sites E (17 $51.935^{\prime} \mathrm{S} 44^{\circ} 32.869^{\prime} \mathrm{W}, 517 \mathrm{~m}$ a.s.1.) and F (17 ${ }^{\circ} 51.928^{\prime} \mathrm{S}$ $44^{\circ} 33.008^{\prime} \mathrm{W}, 519 \mathrm{~m}$ a.s.l.) (Supplementary data)] were located further north in Lassance. On the left bank, one trap was hung in a hen house and two were hung in the gallery forest. On the right bank, three traps were hung in the galery forest (Supplementary data). The average width of the river in this area was $166 \mathrm{~m}$. The distance between collection areas A, B and C, D was $6.9 \mathrm{~km}$ and the distance between sites C, D and E, F was $5.8 \mathrm{~km}$. All collection points were situated in the same hypsometric range (from 494-571 $\mathrm{m}$ a.s.1.).

Phlebotomine identification - The collected sandflies were identified according to the classification proposed by Galati (2003). The morphological characters used to distinguish males from females of $N y$. intermedia and Ny. neivai were described by Marcondes et al. (1997) and Andrade Filho et al. (2003).

Description of the sampled areas - A summarised description of the areas was produced during the field collections. The areas were characterised according to the degree of human modification. The aspects observed concern the vegetation and the presence of both dwellings and animal shelters (Supplementary data).

Climatic data - Climatic data were obtained from the National Institute of Meteorology (Ministry of Agriculture, Livestock and Supply, 5th District of Meteorology, Pirapora e Corinto Stations).

Analyses - The data on the Ny. intermedia and $N y$. neivai populations were analysed in relation to the banks of the Velhas River, precipitation, humidity, temperature, season of the year and the degree of anthropogenic modification of the areas.

The data were organised using Excel 97/2003, which was employed to calculate descriptive statistics. GraphPad Prism 4.0 was used for statistical analyses. The chisquare two-sided degree of freedom $=1$ test was used to compare the proportions of specimens per species collected on each bank of the river.

\section{RESULTS}

The enviromental characterisation demonstrated that the study areas presented different degrees of anthropogenic modification. The right bank of the Velhas River was more preserved, exhbiting medium and large-sized trees and fewer human dwellings and animal shelters. The left bank was more modified, showing the presence of human dwellings and animal shelters (Supplementary data).

A total of 21,050 sandfly specimens were collected. The majority of the specimens $(20,508,97 \%)$ were identified as $N y$. intermedia $(2,817,13 \%)$ and $N y$. neivai $(17,691,84 \%)$. The total sex ratio (M:F) was 1:1.05. The sex ratio for $N y$. intermedia was 1:0.41 during the first year, 1:1.01 during the second year and 1:0.54 over the entire period. The $N y$. neivai sex ratio was 1:1.06 during the first year, 1:2.08 during the second year and 1:1.16 for the entire period.

A greater number of sandflies was collected on the right bank than on the left bank during both periods. The 
proportions of the $N y$. intermedia and $N y$. neivai specimens collected were significantly different during both periods (chi-squared test, $\mathrm{p}<0.0001$ ). $N y$. neivai was the predominant species observed during both periods and for all of the study sites (Fig. 2, Tables I, II).

Comparing Supplementary data and Table I, it appears that the human modifications in the study area (changes in phyto-physiognomy and the presence of both animal shelters and human dwellings) might be associated with the decrease in the number of sandflies in this region. The difference between the proportions of $N y$. neivai specimens on each bank was statistically significant, with a greater number observed on the right bank (Table I).

The number of $N y$. neivai specimens predominated over that of $N y$. intermedia during both periods; the ratio of $N y$. neivai to $N y$. intermedia was 7.54 for the first period and 2.99 for the second (Table II).

Regarding the seasonal variation in the first period, the peak in the number of insects collected was observed after the rainy periods (from February-May 2004), which coincided with periods of high relative humidity (83-
$74 \%$ ) and high temperatures $\left(23 \cdot 3-23 \cdot 7^{\circ} \mathrm{C}\right) . N y$. neivai was the most frequent and abundant species in all of the months studied, being collected at least twice as often as Ny. intermedia (Fig. 2, Table II) in this period.

In the second period, the sandfly distribution pattern was slightly different, with peaks occurring during different months (October 2004, March 2005 and June 2005) (Fig. 2). The highest peak was observed in March, when heavy rainfall $(302 \mathrm{~mm})$ and high humidity and temperatures occurred. Although $N y$. neivai was the most abundant species, the total numbers of $N y$. neivai and $N y$. intermedia specimens collected were more similar during the second period. Ny. intermedia was more abundant than $N y$. neivai only during August and November of 2004 (Fig. 2, Table II).

\section{DISCUSSION}

Although there have been several studies on sandflies in Brazil, their scope has generally been restricted to one phytogeographic zone according to Dias-Lima et al. (2003). Few studies have addressed the ecological features of the sandfly populations and a majority of the studies fo-

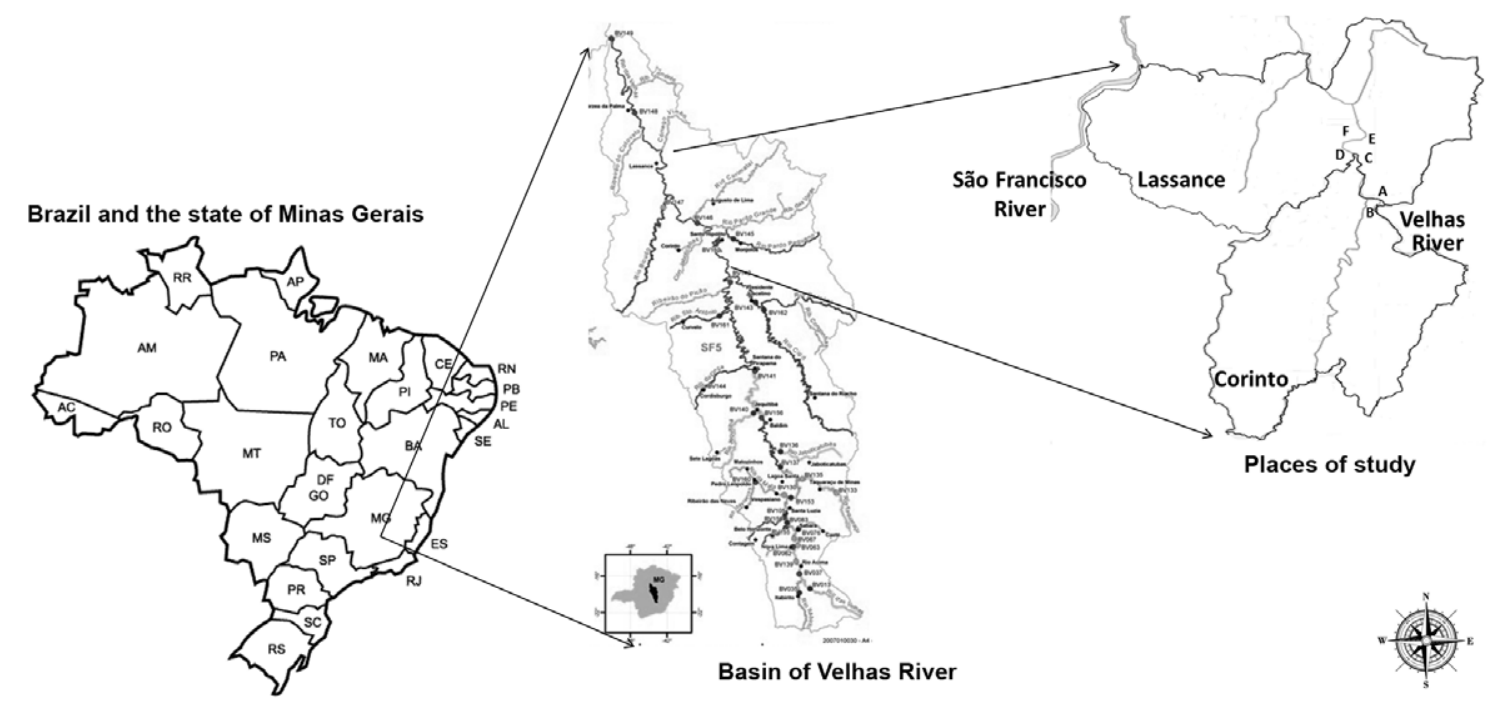

Fig. 1: map of the region bordering the municipalities of Corinto and Lassance, Minas Gerais, Brazil and location of collection points A-F according to Table I.
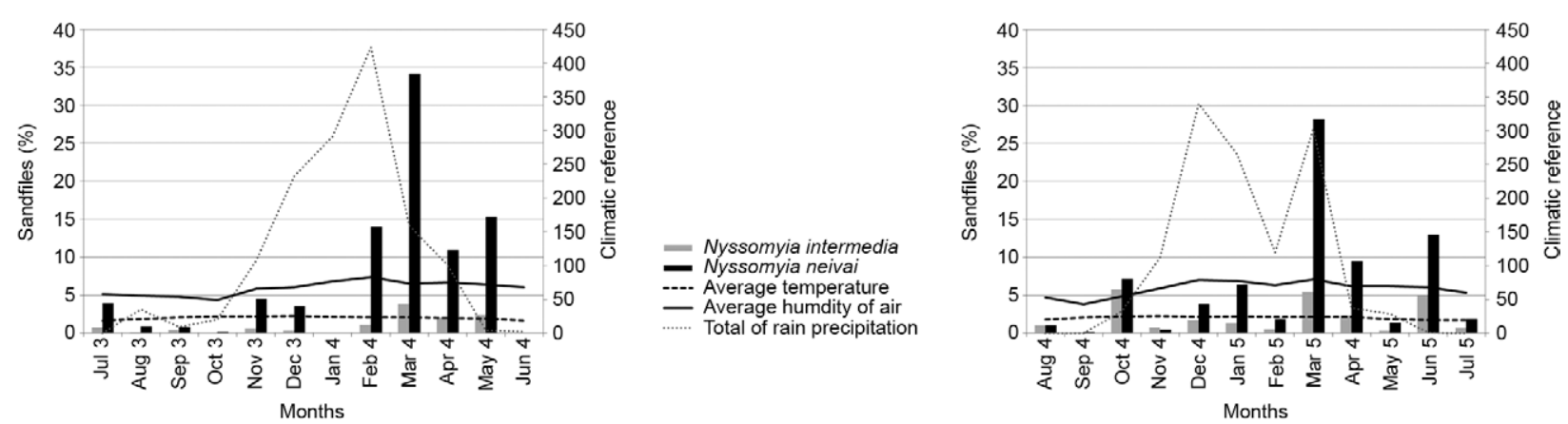

Fig. 2: month distribution of $N y$. neivai and Ny. intermedia collected in the region of Corinto and Lassance, Minas Gerais, Brazil from July 2003-June 2004 (1st period) and from August 2004-July 2005 (2nd period). 
cus principally on the importance of these insects in terms of the epidemiology of the leishmaniasis cycle.

However, some studies have found differences between sandfly populations in various geographical areas characterised by different degrees of anthropogenic change. Additionally, some authors have reported differences between the sandfly populations found in pastures, orchards, intradomiciliary and peridomiciliary areas and primary forests (Andrade Filho et al. 2001, de Luca et al. 2003).
$N y$. intermedia and Ny. neivai occur in sympatry and represent the dominant species of sandflies in the study area, constituting approximately $100 \%$ of the sandflies collected in Corinto and Lassance (Fig. 1). Similar results were observed by Galati et al. (2010) in a study involving both species, also in a sympatric area, in which the two species accounted for a total of $97.9 \%$ of the phlebotomines captured.

Previous studies of the sandfly fauna have recorded 19 species in Lassance and Corinto and important vec-

TABLE I

Sandflies collections per bank of the Velhas River and period of study in the region of Lassance and Corinto, Minas Gerais, Brazil from July 2003-June 2005

Left bank

\begin{tabular}{|c|c|c|c|c|c|c|c|}
\hline \multirow[b]{2}{*}{ Species/sex } & \multicolumn{3}{|c|}{ First period } & \multicolumn{3}{|c|}{ Second period } & \multirow[b]{2}{*}{ Total } \\
\hline & Site A & Site C & Total & Site C & Site E & Total & \\
\hline Nyssomyia intermedia/M & 35 & 202 & 237 & 121 & 15 & 136 & 373 \\
\hline Ny.intermedia/F & 59 & 395 & 454 & 114 & 23 & 137 & 591 \\
\hline Subtotal & 94 & 597 & 691 & 235 & 38 & 273 & $964^{a}$ \\
\hline Nyssomyia neivai/M & 1,294 & 1,732 & 3,026 & 159 & 24 & 183 & 3,209 \\
\hline Ny. neivai/F & 1,432 & 1,570 & 3,002 & 87 & 21 & 108 & 3,110 \\
\hline Subtotal & 2,726 & 3,302 & 6,028 & 246 & 45 & 291 & $6,319^{a}$ \\
\hline Total & 2,820 & 3,899 & 6,719 & 481 & 83 & 564 & 7,283 \\
\hline
\end{tabular}

Right bank

\begin{tabular}{lccccccc} 
Species/sex & Site B & Site D & Total & Site D & Site F & Total & Total \\
\hline Ny. intermedia/M & 27 & 335 & 362 & 99 & 157 & 256 & 618 \\
Ny. intermedia/F & 107 & 878 & 985 & 75 & 175 & 250 & 1,235 \\
Subtotal & 134 & 1,213 & 1,347 & 174 & 332 & 506 & $1,853^{a}$ \\
Ny. neivai/M & 1,076 & 3,820 & 4,896 & 543 & 845 & 1,388 & 6,284 \\
Ny. neivai/F & 1,364 & 3,076 & 4,440 & 233 & 415 & 648 & 5,088 \\
Subtotal & 2,440 & 6,896 & 9,336 & 776 & 1,260 & 2,036 & $11,372^{a}$ \\
\hline Total & 2,574 & 8,109 & 10,683 & 950 & 1,592 & 2,542 & 13,225 \\
\hline
\end{tabular}

$a: \mathrm{p}<0.0001$.

TABLE II

Nyssomyia neivai/Nyssomyia intermedia ratios in the region of Corinto and Lassance, Minas Gerais, Brazil in both banks of the Velhas River, by month from July 2003-June 2004 (1st period) and from August 2004-July 2005 (2nd period)

\begin{tabular}{lccccccccccccc}
\hline $\begin{array}{l}\text { First period } \\
\text { Month }\end{array}$ & Jul 3 & Aug 3 & Sep 3 & Oct 3 & Nov 3 & Dec 3 & Jan 4 & Feb 4 & Mar 4 & Apr 4 & May 4 & Jun 4 & Total \\
\hline Total & 5.36 & 8.32 & 2.00 & 2.31 & 7.50 & 10.30 & 0.00 & 12.56 & 8.98 & 5.20 & 6.38 & 3.50 & 7.54 \\
\hline $\begin{array}{l}\text { Left bank } \\
\text { Right bank }\end{array}$ & 0.56 & 0.86 & 1.11 & 2.00 & 5.55 & 6.63 & 0.00 & 24.57 & 10.29 & 9.09 & 8.06 & 6.00 & 8.72 \\
& 6.15 & 12.67 & 5.00 & 2.42 & 12.62 & 19.59 & 0.00 & 8.25 & 8.54 & 4.12 & 4.97 & 1.00 & 6.93 \\
\hline $\begin{array}{l}\text { Second period } \\
\text { Month }\end{array}$ & Aug 4 & Sep 4 & Oct 4 & Nov 4 & Dec 4 & Jan 5 & Feb 5 & Mar 5 & Apr 5 & May 5 & Jun 5 & Jul 5 & Total \\
\hline Total & 0.97 & 1.20 & 1.23 & 0.61 & 2.22 & 5.00 & 3.69 & 5.18 & 4.04 & 3.91 & 2.63 & 2.64 & 2.99 \\
\hline $\begin{array}{l}\text { Left bank } \\
\text { Right bank }\end{array}$ & 0.62 & 0.60 & 0.16 & 0.55 & 0.21 & 0.96 & 0.00 & 6.29 & 1.10 & 1.25 & 0.52 & 1.20 & 1.07 \\
\hline
\end{tabular}


tor species implicated in the transmission of Leishmania have been collected (Saraiva et al. 2008). The putative and proven vectors collected included $N y$. intermedia, Ny. neivai, Nyssomyia whitmani (Antunes \& Coutinho 1939), Lutzomyia longipalpis (Lutz \& Neiva 1912) and Migonemyia migonei (França 1920) and both Ny. neivai and Evandromyia sallesi (Galvão \& Coutinho 1939) were found to be infected by Leishmania infantum chagasi in this area (Saraiva et al. 2009).

Some authors have reported alternating dominance of one of the two species in places where they occur in sympatry (Andrade Filho et al. 2003, 2007). However, $N y$. neivai was found to be the most abundant species in both of the periods of collection and all of the locations analysed in this study (Table I, Chart 2). Therefore, based on the hypothesis of competition between the two species, it is possible to infer that $N y$. neivai displays greater a ability to exploit the investigated habitats.

The sex ratio varied during the two study periods for both species. It is difficult to explain this variation, as there are many factors that might affect the number of males and females collected. Among these factors, physiological status may represent the factor that contributes most to this variation.

In the present study, the observed abundance of $N y$. neivai suggests that it is one of the species that is most likely to act as the primary vector of ATL, although the values obtained for $\mathrm{Ny}$. intermedia suggest that it also is associated with Leishmania transmission in this region. Both species have been found to be naturally infected with Leishmania and are associated with ATL foci (Forattini et al. 1972, Rangel et al. 1984, Casanova et al. 1995, Córdoba-Lanus et al. 2006, Marcondes et al. 2009, Saraiva et al. 2009, 2010, Pita-Pereira et al. 2009, Margonari et al. 2010, Oliveira et al. 2011), thereby demonstrating the great epidemiological importance of these species.

Lutz and Neiva (1912) have reported that $N y$. intermedia presents a synanthropic habit, also affirmed by Rangel et al. (1986), who described the highly anthropophilic behaviour of leishmaniasis in the state of Rio de Janeiro, Brazil. In the state of São Paulo, Ny. neivai was predominantly collected with a Disney trap using a dog as bait and blood meal identification revealed the preference of this species for human blood, followed by that of birds (Casanova 2001).

Comparison of the environmental data (Table I) and the data on the relative abundance of species (Tables I, II) demonstrated the more frequent occurrence of $N y$. neivai compared to $N y$. intermedia in all of the studied environments. The difference between the proportions of the specimens of the two species collected on the left and right banks was statistically significant $(\mathrm{p}<0.0001)$. The left bank displayed a smaller number of collected specimens, with a lower relative abundance of $N y$. neivai being recorded in both study periods (Table I). These data might support the hypothesis that anthropic modifications have both reduced the abundance of specimens and modified the population structure of this insect group in the region and period studied.

The pattern of seasonal variation on the two banks was similar (Fig. 2), with the period of the greatest occurrence of sandflies coinciding with the late summer and early spring. This period corresponds to the end of the rainy season and is characterised by high relative humidity in the studied region. The seasonal pattern is mainly determined by the species $N y$. neivai and $N y$. intermedia. $N y$. neivai was collected in greater numbers in 21 of the 24 months sampled on both banks (Fig. 2, Table II).

Several studies have shown that anthropic modifications may favour populations of some species that colonise anthropised environments, as was observed for $L u$. longipalpis in urban areas of Brazil. However, urban areas display reduced levels of species richness compared to wild areas. For example, some studies on the sandfly populations in the metropolitan region of Belo Horizonte have demonstrated a higher frequency of $N y$. whitmani in green areas close to urban zones, while Lu. longipalpis is most frequent in urban areas. Therefore, we may infer that urbanisation alters species dynamics, thereby favouring those species that are most adapted to anthropically modified environments (Souza et al. 2004, Resende et al. 2006, Carvalho et al. 2010, Saraiva et al. 2010).

The left bank present a higher degree of anthropic modification and a slightly higher species richness and diversity than the right bank (Saraiva et al. 2008). This pattern can be explained by the wider range of habitats present in an environment characterised by a greater degree of anthropic change, though that is less drastic compared to the process of urbanisation. We assume that anthropogenic interference destabilises ecological communities and redirects the succession process. Intermediate disturbance in ecosystems leads to intermediate successional stages, associated with higher rates of biodiversity (Begon et al. 2007).

It is necessary to emphasise that it is impossible to conclude that the river acts as a geographical barrier between the $N y$. neivai and $N y$. intermedia populations, although this has been established in other regions (Marcondes et al. 1998), as the environmental differences alone might explain the results and genetic analysis was not performed.

In a previous study, the São Francisco River was found to play an important role in the speciation of $L u$. longipalpis, leading to the development of sibling species (Coutinho-Abreu et al. 2008). In that study, the authors analysed sequences of the cytochrome $b$ gene. Thus, we believe that the present study highlights the need for analysis of the genetic structure of the populations of these two sandfly species on the left and right banks of the Velhas River to assist in the interpretation of the ecological patterns that were observed.

\section{ACKNOWLEDGEMENTS}

To all the people of the communities of Corinto and Lassance, for the cooperation on this project, to the professional drivers, for participation, and to the CRNIF professionals involved in any away in the laboratory and field work.

\section{REFERENCES}

Andrade Filho JD, Galati EAB, Falcão AL 2003. Redescription of Nyssomyia intermedia (Lutz \&Neiva, 1912) and Nyssomyia neivai (Pinto, 1926) (Diptera: Psychodidae). Mem Inst Oswaldo Cruz 98: 1059-1065.

Andrade Filho JD, Galati EAB, Falcão AL 2007. Nyssomyia intermedia (Lutz \& Neiva, 1912) and Nyssomyia neivai (Pinto, 1926) (Diptera: 
Psychodidae: Phlebotominae) geographical distribution and epidemiological importance. Mem Inst Oswaldo Cruz 102: 481-487.

Andrade Filho JD, Valente MB, Andrade WA, Brazil RP, Falcão AL 2001. Flebotomíneos do estado de Tocantins, Brasil (Diptera: Psychodidae). Rev Soc Bras Med Trop 34: 323-329.

Begon M, Townsend CR, Harper JL 2007. A natureza da comunidade: padrões no espaço e no tempo. In M Begon, CR Townsend, JL Harper, Ecologia: de indivíduos a ecossistemas, Artmed, Porto Alegre, p. 469-498.

Carvalho GML, Gontijo CMF, Falcão AL, Andrade Filho JD 2010. Study of phlebotomine sand flies (Diptera: Psychodidae) collected in a Leishmania-endemic area of the metropolitan region of Belo Horizonte, Brazil. J Med Entomol 47: 972-976.

Casanova C 2001. Avaliação do potencial biológico de Lutzomyia intermedia s.l. como vetor da leishmaniose tegumentar americana na zona rural do município de Conchal, estado de São Paulo, PhD Thesis, Faculdade de Saúde Pública da Universidade de São Paulo, São Paulo, 99 pp.

Casanova C, Mayo RC, Rangel O, Mascarini LM, Pignatti MG, Galati EAB, Gomes AC 1995. Natural Lutzomyia intermedia (Lutz \& Neiva) infection in the valley of the Mogi Guaçu River, state of São Paulo, Brazil. Bol Dir Malariol San Amb 35 (Suppl. 1): 77-84.

Córdoba-Lanus E, de Grosso ML, Piñero JE, Valladares B, Salomón OD 2006. Natural infection of Lutzomyia neivai with Leishmania spp in northwestern Argentina. Acta Trop 98: 1-5.

Coutinho-Abreu IV, Sonoda IV, Fonseca JA, Melo MA, Balbino VQ, Ramalho-Ortigão M 2008. Lutzomyia longipalpis s.l. in Brazil and the impact of the São Francisco River in the speciation of this sand fly vector. Parasit Vectors 1: 16.

de Luca AS, Vasconcelos HL, Barrett TV 2003. Distribution of sandflies (Diptera: Phlebotominae) in forest remnants and adjacent matrix habitats in Brazilian Amazonia. Braz J Biol 63: 401-410.

Dias-Lima AG, Guedes MLS, Sherlock IA 2003. Horizontal stratification of the sand fly fauna (Diptera: Psychodidae) in a transitional vegetation between caatinga and tropical rain forest, state of Bahia, Brazil. Mem Inst Oswaldo Cruz 98: 733-737.

Falcão AR 1981. Um novo modelo de armadilha luminosa de sucção para pequenos insetos. Mem Inst Oswaldo Cruz 76: 303-305.

Forattini OP, Pattoli DBG, Rebello EX, Ferreira AO 1972. Infecção natural de flebotomíneos em foco enzoótico de leishmaniose no estado de São Paulo, Brasil. Rev Saude Publica 6: 431-433.

Galati EAB 2003. Classificação de Phlebotominae. In EF Rangel, R Lainson (eds.), Flebotomíneos do Brasil, Editora Fiocruz, Rio de Janeiro, p. 23-52.

Galati EAB, Massará AM, Gonçalves-Andrade RM, Bueno EFM, Paiva BR, Malafronte RS 2010. Nyssomyia intermedia (Lutz \& Neiva) and Nyssomyia neivai (Pinto, 1926) (Diptera, Psychodidae, Phlebotominae) in a sympatric area: seasonal and nocturnal hourly rhythm in black and white modified Shannon traps. Rev Bras Entomol 54: 677-686.

Lutz A, Neiva A 1912. Contribuição para o conhecimento das espécies do gênero Phlebotomus existentes no Brasil. Mem Inst Oswaldo Cruz: 4: 84-95.

Marcondes CB, Bittencourt IA, Stoco PH, Eger I, Grisard EC, Steindel M 2009. Natural infection of Nyssomyia neivai (Pinto, 1926) (Diptera: Psychodidae, Phlebotominae) by Leishmania (Viannia) spp in Brazil. Trans R Soc Trop Med Hyg 103: 1093-1097.

Marcondes CB, Day JD, Ready PD 1997. Introgression between Lutzomyia intermedia and both $L u$. neivai and $L u$. whitmani and their roles as vectors of Leishmania braziliensis. Trans $R$ Soc Trop Med Hyg 91: 725-726.

Marcondes CB, Lozovei AL, Vilela JH 1998. Geographic distribution of phlebotomine sandflies of the Lutzomyia intermedia (Lutz \& Leiva, 1912) complex (Diptera, Psychodidae). Rev Soc Bras Med Trop 31: 51-58.

Margonari C, Soares RP, Andrade-Filho JD, Xavier DC, Saraiva L, Fonseca AL, Silva RA, Oliveira ME, Borges EC, Sanguinette CC, Melo MN 2010. Phlebotomine sand flies (Diptera: Psychodidae) and Leishmania infection in Gafanhoto Park, Divinópolis, Brazil. J Med Entomol 47: 1212-1219.

MS - Ministério da Saúde Brasil 2006. Manual de controle da leishmaniose visceral. [cited 2012 Jan 11]. Available from: portalsaude.gov.br/portal/arquivos/pdf/manual_leish_visceral2006.pdf.

Myers N, Mittermeier RA, Mittermeier CG, Fonseca GAB, Kent J 2000. Biodiversity hotspots for conservation priorities. Nature 403: 853-858.

Oliveira DM, Reinhold-Castro KR, Bernal MVZ, Legriffon CMO, Lonardoni MVC, Teodoro U, Silveira TGV 2011. Natural infection of Nyssomyia neivai by Leishmania (Viannia) spp in the state of Paraná, southern Brazil, detected by multiplex polymerase chain reaction. Vector Borne Zoonotic Dis 11: 137-143.

Pita-Pereira D, Souza GD, Zwetsch A, Alves CR, Britto C, Rangel EF 2009. First report of Lutzomyia (Nyssomyia) neivai (Diptera: Psychodidae: Phlebotominae) naturally infected by Leishmania (Viannia) braziliensis in a periurban area of South Brazil using a multiplex polymerase chain reaction assay. Am J Trop Med Hyg 80: 593-595.

Rangel EF, Souza NA, Wermelinger ED, Azevedo ACR, Barbosa AF, Andrade CA 1986. Flebótomos de Vargem Grande, foco de leishmaniose tegumentar no estado do Rio de Janeiro. Mem Inst Oswaldo Cruz 81: 347-349.

Rangel EF, Souza NA, Wermelinger ED, Barbosa AF 1984. Infecção natural de Lutzomyia intermedia (Lutz \& Neiva, 1912) em área endêmica de leishmaniose tegumentar no Estado do Rio de Janeiro. Mem Inst Oswaldo Cruz 79: 395-396.

Resende MC, Camargo MC, Vieira JR, Nobi RC, Porto MN, Oliveira CD, Pessanha JE, Cunha MC, Brandão ST 2006. Seasonal variation of Lutzomyia longipalpis in Belo Horizonte, state of Minas Gerais. Rev Soc Bras Med Trop 39: 51-55.

Saraiva L, Andrade Filho JD, Silva SO, Andrade ASR, Melo MN 2010. The molecular detection of different Leishmania species within sand flies from a cutaneous and visceral leishmaniasis sympatric area in Southeastern Brazil. Mem Inst Oswaldo Cruz 105: 1033-1039.

Saraiva L, Carvalho GML, Gontijo CMF, Quaresma PF, Lima ACVMR, Falcão AL, Andrade Filho JD 2009. Natural infection of Lutzomyia neivai and Lutzomyia sallesi (Diptera: Psychodidae) by Leishmania infantum chagasi in Brazil. J Med Entomol 46: 1159-1163.

Saraiva L, Carvalho GML, Sanguinette CC, Carvalho DAA, Falcão AL, Andrade Filho JD 2008. Sandflies (Diptera: Psychodidae: Phlebotominae) collected on the banks of the Velhas River in the state of Minas Gerais, Brazil. Mem Inst Oswaldo Cruz 103: 843-846.

Souza CM, Pessanha JE, Barata RA, Monteiro EM, Costa DC, Dias ES 2004. Study on phlebotomine sand fly (Diptera: Psychodidae) fauna in Belo Horizonte, state of Minas Gerais, Brazil. Mem Inst Oswaldo Cruz 99: 795-803.

WWF - Worl Wildlife Found Brasil 2011. Biomas Brasileiros. [cited 2012 Feb 11]. Avaiable from: wwf.org.br/natureza_brasileira/ questoes_ambientais/biomas/. 
Environmental characteristics of the banks of the Velhas River in the region of Lassance and Corinto, Minas Gerais, Brazil

\begin{tabular}{|c|c|c|c|}
\hline Municipality & Places & Characteristics & Figure \\
\hline \multirow[t]{2}{*}{ Corinto } & A & $\begin{array}{l}\text { Left bank: gallery forest with high level of anthropogenic modification. } \\
\text { There were smallholder farmers and fishermen ranches. }\end{array}$ & 2 \\
\hline & $\mathrm{B}$ & Right bank: gallery forest, relatively well preserved. Presence of large and medium size trees. & 3 \\
\hline \multirow[t]{4}{*}{ Lassance } & $\mathrm{C}$ & $\begin{array}{l}\text { Left bank: gallery forest with high level of anthropogenic modification. } \\
\text { There were smallholder farmers and fishermen ranches. }\end{array}$ & 4 \\
\hline & $\mathrm{D}$ & Right bank: gallery forest relatively well preserved. Presence of large and medium size trees. & 5 \\
\hline & $\mathrm{E}$ & $\begin{array}{l}\text { Left bank: gallery forest with medium level of anthropogenic modification. } \\
\text { Only one human dwelling with a shelter for hens. }\end{array}$ & 6 \\
\hline & $\mathrm{F}$ & Right bank: gallery forest relatively well preserved. Presence of large and medium trees. & 7 \\
\hline
\end{tabular}
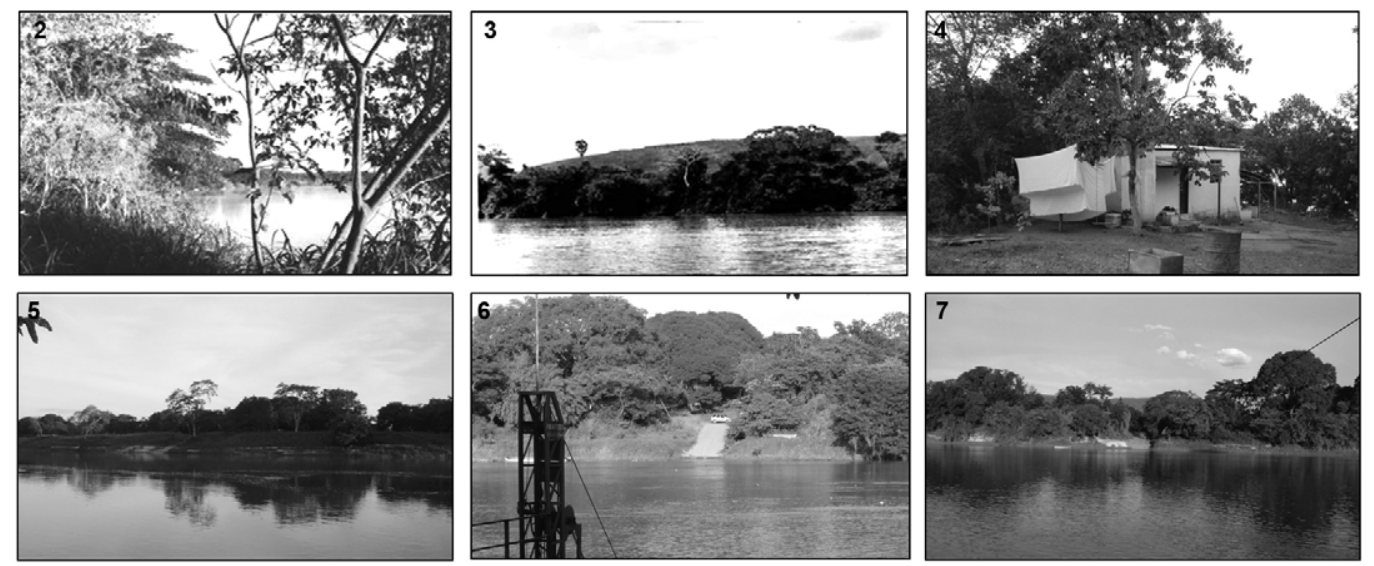

Figs 2-7: enviromental characteristis of the collection places according to Table I. 2: place A, Corinto, left bank; 3: place B, Corinto, right bank; 4: place C, Lassance, left bank; 5: place D, Lassance, right bank; 6: place E, Lassance, left bank; 7: place F, Lassance, right bank. 